\title{
Comparison of intra-oral mask and classic face mask in terms of ventilation success and practitioners' work load assessments: a randomized crossover study
}

\author{
Mikail ALKAN ${ }^{1}$, İsmail Aytaç ${ }^{1}$, Betül GÜVEN AYTAÇ ${ }^{1}$, Hidayet ÜNAL ${ }^{1}$, Bahattin \\ GÜRSUL ${ }^{1}$, Semih Baskkan ${ }^{1}$, Aysun POSTACI ${ }^{1}$, and Nermin GÖĢ̆̈̈ş ${ }^{1}$ \\ ${ }^{1}$ Ankara Numune Training and Research Hospital
}

April 30, 2021

\begin{abstract}
Aim: Providing effective ventilation of the unconscious patient is an essential skill in every specialty dealing with airway management. In this randomized cross-over study aimed to compare intra-oral and classic face mask in terms of ventilation success of patients, practitioners' workload and anxiety assessments. Also we analyzed potential risk factors of difficult mask ventilation for both masks. Methods: 24 anesthesiology residents and 12 anesthesiologists participated in the study. Each of the practitioners ventilated 4 patients with both masks at settled pressure and frequency. Practitioners rated their workload and anxiety related to masks with National Aeronautics and Space Administration Task Load Index score and State Trait Anxiety Inventory scale. Ventilation success was evaluated with Han scale, expiratory tidal volume and leak volume. We analyzed potential risk factors of difficult mask ventilation with anthropometric characteristics and STOP-BANG score. Results: Ventilation success rate was superior with intraoral mask comparing to classic face mask in terms of Han Scale (Easy mask ventilation percentage 84/144 (58.3\%); 123/144 (85.4\%); respectively) and tidal volume (481.92 $\pm 173.99 ; 430.85 \pm 154.87 \mathrm{~mL}$; respectively). Leak volume in intraoral mask ventilation was significantly lower than classic face mask (71.50 $\pm 91.17 / 159.38 \pm 146.31$ respectively). Diffucult mask ventilation risk factors were high weight, neck circumference, Mallampati score and STOP-BANG score $>3$ for classic face mask (at the utmost neck circumference 95\% CI, OR=1.180, $\mathrm{p}=0.002$ ) Risk factors were high body mass index and Mallampati score for intraoral mask (at the utmost Body mass index 95\% CI, OR=1.162 $\mathrm{p}=0.006$ ). The anxiety ratings of practitioners were similar between two masks. The work-load rating is higher with intraoral mask comparing to classic face mask. Conclusion: Intraoral mask may be an effective alternative device for bag-valve mask ventilation.
\end{abstract}

Comparison of intra-oral mask and classic face mask in terms of ventilation success and practitioners' work load assessments: a randomized crossover study

Aim: Providing effective ventilation of the unconscious patient is an essential skill in every specialty dealing with airway management. In this randomized cross-over study aimed to compare intra-oral and classic face mask in terms of ventilation success of patients, practitioners' workload and anxiety assessments. Also we analyzed potential risk factors of difficult mask ventilation for both masks.

Methods: 24 anesthesiology residents and 12 anesthesiologists participated in the study. Each of the practitioners ventilated 4 patients with both masks at settled pressure and frequency. Practitioners rated their workload and anxiety related to masks with National Aeronautics and Space Administration Task Load Index score and State Trait Anxiety Inventory scale. Ventilation success was evaluated with Han scale, expiratory tidal volume and leak volume. We analyzed potential risk factors of difficult mask ventilation with anthropometric characteristics and STOP-BANG score. 
Results: Ventilation success rate was superior with intraoral mask comparing to classic face mask in terms of Han Scale (Easy mask ventilation percentage 84/144 (58.3\%); 123/144 (85.4\%); respectively) and tidal volume $(481.92 \pm 173.99 ; 430.85 \pm 154.87 \mathrm{~mL}$; respectively). Leak volume in intraoral mask ventilation was significantly lower than classic face mask $(71.50 \pm 91.17 / 159.38 \pm 146.31$ respectively).

Diffucult mask ventilation risk factors were high weight, neck circumference, Mallampati score and STOPBANG score $>3$ for classic face mask (at the utmost neck circumference 95\% CI, OR=1.180, $\mathrm{p}=0.002$ ) Risk factors were high body mass index and Mallampati score for intraoral mask (at the utmost Body mass index $95 \% \mathrm{CI}, \mathrm{OR}=1.162 \mathrm{p}=0.006)$.

The anxiety ratings of practitioners were similar between two masks. The work-load rating is higher with intraoral mask comparing to classic face mask.

Conclusion: Intraoral mask may be an effective alternative device for bag-valve mask ventilation.

Key words : Difficult mask ventilation; Face mask; Han scale; Intraoral mask; STOP BANG score

\section{INTRODUCTION AND AIM}

Providing effective ventilation of the unconscious patient during either resuscitation or general anesthesia induction and wake-up period is an essential skill in every specialty dealing with airway management. Adequate mask ventilation has become an important focus in the difficult airway algorithms' various stages 1,2 .

Determining risk factors for difficult mask ventilation (DMV) ${ }^{3}$ and providing preoxygenation ${ }^{4}$ before induction of anesthesia considering the possibility of DMV have utmost importance in operation theaters, emergency and intensive care units (ICU) ${ }^{5}$.

Classic Face mask (CFM) ventilation is frequently applied also during non-operating room anesthesia, in or out-of hospital cardiac arrests etc. by auxiliary medical personnel and specialists not as familiar as anesthesiologists ${ }^{6}$.

It is emphasized that healthcare workers responsible for airway management should be familiar with different devices and techniques that may have advantages in certain situations ${ }^{7}$.

Although mask ventilation is life-saving and important, this topic has been given little coverage in the widespread scientific literature and book chapters on airway management ${ }^{8}$.

An important cause of difficult mask ventilation is gas leakage from improper seal besides resistance of the airway to the gas inlet or outlet ${ }^{9}$.

Improper seal between the CFM and the patient's face may occur because of beard, facial anatomical deformity, toothlessness and etc. Additionally facemasks somewhat increases dead space and may cause insufficiency of tidal volume ${ }^{10}$.

Practitioners commonly grasp the CFM with the thumb and index fingers in the form of $\mathrm{C}$ and place the $\mathrm{CFM}$ on the face of the patient, while raising the mandible with the other fingers in the form of $\mathrm{E}$ letter although there are some alternative grips ${ }^{11}$ (Figure 1).

Intraoral mask (IOM) is an alternative mask which is placed in the mouth between the lips and teeth like a snorkel. Practitioners close the nose with the tips of the thumb and index finger then with other finger grasp and raise the mandible and close the mouth. IOM may have advantages in situations as improper seal with the CFM. IOM also may have some advantages for preoxygenization and can be used for non-invasive ventilation ${ }^{12-18}$ (Figure 2).

In this randomized observer blinded cross-over study we compared the IOM and CFM (AMS) in terms of the effectiveness of ventilation and practitioners' anxiety/workload evaluation related to the masks. Secondly we aimed to investigate the factors likely to cause and incidence of DMV for two masks. 


\section{MATERIAL AND METHODS:}

After obtaining ethics committee approval (Ankara Numune Education and Research Hospital Ethics Committee, numbered E-15-666 and dated 20/01/2016) and written informed consent from patients and practitioners, this single-center, prospective, randomized, observer-blinded cross-over study was conducted between January 2016 and March 2016.

24 anesthesiology residents and 12 specialist anesthesiologists participated in the study in the general surgery operation theatre. Each of the practitioners ventilated 4 patients with non-dominant hand. Each of the patients ventilated with IOM (NuMASK $\mathrm{R})$ ) and CFM (AMS) at settled pressure (20 $\mathrm{cmH} 20)$ and frequency

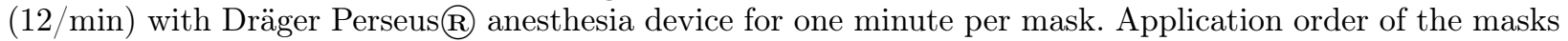
was determined by the closed envelope method. Mask ventilation efficiency of 144 ASA I-II-III patients aged 18-65 years was evaluated.

The exclusion criteria of our study were as follows; initial SPO2 value $<95 \%$, severe pulmonary or cardiac diseases, tumor or goiter restricting the airway, tooth mobility and $\mathrm{SPO} 2<90 \%$ during mask ventilation for any reason

The State-Trait Anxiety Inventory TX-2 (Trait Anxiety Scale Scoring) levels, age, gender, and years of anesthesia experience of the participants were recorded.

In preoperative examination patient's name, protocol number, age, gender, comorbidities, ASA score, Mallampati score, weight, height, Body mass index (BMI), neck circumference(NC), thyromental distance (TMD), sternomental distance (SMD), hyo-mental distance (HMD), interincisor distance (IID), whether he had teeth, whether he had a beard, and whether there was any limitation in neck movements were recorded.

The risk of Obstructive Sleep Apnea was determined with the STOP-Bang Scoring Model ${ }^{19}$. Patients who answered yes to 3 or more questions were registered as high risk of OSAS (STOP_BANG[?]3), and patients who answered yes to less than 3 questions (STOP_BANG $<3$ ) were recorded as low risk of OSAS.

Anesthesia was induced with $0.05 \mathrm{mg} \cdot \mathrm{kg}^{-1}$ midazolam, $1.0 \mathrm{mcg} \cdot \mathrm{kg}^{-1}$ fentanyl, $2 \mathrm{mg} . \mathrm{kg}^{-1}$ propofol and $0.5 \mathrm{mg} . \mathrm{kg}^{-1}$ rocuronium after eight hours of fasting. Intraoperative noninvasive blood pressure, electrocardiography, and $\mathrm{SpO}_{2}$ were performed. The patient was placed comfortably in the supine and sniffing position. The practitioner firstly ventilated the patient for 1 minute with the first randomly predetermined mask. Before the second mask, mask ventilation was transferred to an assistant and the practitioner rested for 1 minute. Then the practitioner ventilated for another one minute with the second mask. During ventilation periods a blinded observer recorded mean TV, mean end-tidal carbon dioxide (etCO2) levels, $\mathrm{SpO}_{2}$ and LV for both masks. The effectiveness of ventilation of the masks were also assessed by another observer with the Han Mask Ventilation scale ${ }^{20}$. For Han scale $=\mathrm{I}$ (easy ventilation) ventilation was considered successful. For Han scale $>\mathrm{I}(\mathrm{II}=$ Needs oral airway, $\mathrm{III}=$ requiring two care providers, $\mathrm{IV}=$ unable to mask ventilate $)$ ventilation was considered successful.

After the 4th patient, practitioners completed the State-Trait Anxiety Inventory TX-1 (State-Trait Anxiety Scale Scoring) form and the NASA-TLX (The National Aeronautics and Space Administration-Task Load Index $)^{21}$ forms to measure their anxiety for IOM and CFM. .

\section{STATISTICAL ANALYSIS}

Mean and Standard Deviation, Median, Minimum, Maximum values are given in descriptive statistics for continuous data, and number and percentage values are given in categorical data. SPSS 11.5 program was used in the evaluations and $\mathrm{p}<0.05$ was accepted as the statistical significance limit.

Mann-Whitney U Test / T Test were used according to testing results of the distribution normality for the data obtained by measurement. Chi-Square Test / Fisher's Exact Test were used for categorical data. 
Wilcoxon test / Paired Samples T test was used to compare the SPO2, EtCO2, TV and LV measurements between two masks.

\section{RESULTS}

Demographic and anthropometric characteristics of the patients summarized in Table 1.

Mean TV was higher and Median LW was lower in IOM comparing to CFM(Table 2) but $\mathrm{SPO}_{2}$ and $\mathrm{ETCO}_{2}$ were similar between masks. Successful ventilation(Percentage of the patients with Han Scale=1) were higher in IOM comparing to the CFM (Table 3)

Mean weight of the patients and median of the $\mathrm{NC}$ were higher in unsuccessful mask ventilation(Han Scale $>1$ ) group for $\mathrm{CFM}(\mathrm{p}<0.05)$. Other demographic and anthropometric characteristics were similar between successful and unsuccessful CFM ventilation (Table 4).

Percentage of the patients with Mallampati I and Low OSAS risk (STOP-BANG Score $<3$ ) were higher in successful CFM Ventilation. Gender, ASA and Beard rates were similar between successful and unsuccessful CFM ventilation (Table 5).

Mean BMI of the patients were higher in unsuccessful mask ventilation (Han Scale $>1$ ) comparing to successful IOM ventilation group. Other demographic and anthropometric characteristics were similar between successful and unsuccessful IOM ventilation (Table6).

Percentage of the patients with Mallampati I was higher in successful IOM Ventilation (Table 7) and Gender, ASA, OSAS risk and beard rates were similar between successful and unsuccessful IOM ventilation.

There were no difference between anxiety ratings of practitioners between using CFM and IOM. However practitioners rated the workload for IOM higher in effort, mental demand sections and composite NASA-TLX score than CFM (Table 8).

\section{DISCUSSION}

This study demonstrated that intraoral mask has more easy ventilation rate than classic face mask according to Han Scale (123(85.4), 84(58.3); $\mathrm{n}(\%)$; respectively; $\mathrm{p}=0.000)$. Also it has higher expiratory tidal volume $(481.92+-173.99,430.85+-154.87 \mathrm{~mL}$; respectively; $\mathrm{p}=0.000)$ and decreased air leak volume $(71.50+-91.17$, $159.38+-146.31 \mathrm{~mL}$; respectively; $\mathrm{p}=0.000)$ than classic face mask.

There are very few studies in the scientific literature that discuss the effectiveness of the intraoral mask $12-15,17,22$. The comparisons in terms of the effectiveness of masks in our study are consistent with previous cadaver studies $13,15,17,22$.

According to these results it can be assumed that intraoral mask may have some advantages in difficult mask ventilation situations caused by air leakage due to improper seal. Society of Airway Management recommended using a well-sealed facemask with HEPA filter in suspected COVID-19 patients for pre-oxygenation and ventilation ${ }^{4}$. It can be assumed that decreased air leakage may result less aerosol formation and reduce the likelihood of virus transmission in the COVID-19 era.

Secondly our study demonstrated that practitioners' situational anxiety level obtained from STAI FORM TX1 were similar between intraoral and classic face mask. Despite of these results workload measurements of the practitioners with the NASA task load index (NASA TLX) were higher for intraoral mask than classic facemask. This can be attributed to the users not being familiar with the intraoral mask and their routine use of the classic mask.

There are conflicting results in the literature regarding users' evaluation of intraoral and classic masks. In the study of Riggle et al. ${ }^{12}$ conducted on the airway training manikin, the average muscle pain perceived by the practitioners for both masks was statistically insignificant and most of the practitioners preferred the classical mask; stated that it is easier to grasp, less fatigue and easier to use with the classical mask. The practitioners' evaluations in this study ${ }^{12}$ are consistent with the results of our study. 
However, in terms of workload, the results of our study are contradicted by the fact that McCroy et al. ${ }^{13}$ found the workload of the intraoral mask higher in their study. The reason for this situation may be that practitioners may evaluate the workload of a real mask ventilation application on the patient higher than the workload of a mask ventilation scenario on a cadaver. In addition, in our study, each doctor was given the opportunity to try the mask on 4 different patients instead of a single cadaver, and this situation may have changed the workload assessment due to encountering different patient characteristics.

The main difference of our study from others ${ }^{12,13,15,17,22}$ is that it was performed on real patients under operating room conditions and both masks were used in a large series of patients. Although there are many studies investigating the risk factors for difficult mask ventilation in the literature ${ }^{3,8,9}$, to our knowledge our study is the first study investigating these risk factors for intraoral mask together with the classic mask in the same patient group. Since we have a large patient series, we were able to secondarily investigate the predictors of difficult mask ventilation for both of the masks. We comprehensively investigated the risks of difficult mask ventilation, including the STOP-BANG score, which evaluates the risk of obstructive sleep apnea syndrome along with anthropometric features. The most significant factor among the possible risks for difficult mask ventilation was the neck circumference for the classical mask (other significant factors were body weight, mallampati and stop-bang score). For NuMask the most significant risk factor was BMI and the other was mallampati score. Our results are compatible with a number of risk factors in studies involving a larger number of patients for classic mask ${ }^{3,9}$ and additionally determines risk factors for intraoral mask.

However, there are many limited aspects of our study. It is an important deficiency that the risk factors for difficult mask ventilation are calculated according to the Han scale for patients with $>$ I (II = Needs oral airway, III = requiring two care providers) and do not include real difficult mask ventilation. According to Orbany ${ }^{23}$, the aspects in which Han scale is limited; not validated, not sensitive enough for data comparisons and research purposes, and it is not reproducible. Evaluation is also subjective and observer dependent. Orbany ${ }^{23}$ emphasized that there is no standard definition of difficult mask ventilation based on precise and objective criteria, therefore it is difficult to compare studies and share clinical information. He points out that due to the subjective and practitioner-dependent nature of success in mask ventilation, making such a precise definition is also a difficult goal. However, the risk factors found in our study when considered causally were rational and this limitation is common in other studies ${ }^{8}$.

\section{CONCLUSION}

Intraoral mask can be alternative in difficult mask ventilation situations caused by air leakage due to improper seal. Teaching its use during anesthesia training may lead to more positive results.

\section{REFERENCES}

1. Frerk C, Mitchell VS, McNarry AF, et al. Difficult Airway Society 2015 guidelines for management of unanticipated difficult intubation in adults. BJA: British Journal of Anaesthesia. 2015;115(6):827-848.

2. Gomez-Rios M, Gaitini L, Matter I, Somri M. Guidelines and algorithms for managing the difficult airway. Revista Espanola de Anestesiologia y Reanimacion (English Edition). 2018;65(1):41-48.

3. Norskov A, Wetterslev J, Rosenstock C, et al. Prediction of difficult mask ventilation using a systematic assessment of risk factors vs. existing practice-a cluster randomised clinical trial in 94,006 patients. Anaesthesia. 2017;72(3):296-308.

4. Foley LJ, Urdaneta F, Berkow L, et al. Difficult Airway Management in Adult COVID-19 Patients: Statement by the Society of Airway Management.Anesthesia 83 Analgesia. 2021:10.1213.

5. Higgs A, McGrath B, Goddard C, et al. Guidelines for the management of tracheal intubation in critically ill adults. British journal of anaesthesia. 2018;120(2):323-352.

6. Soleimanpour H, Gholipouri C, Panahi JR, et al. Role of anesthesiology curriculum in improving bagmask ventilation and intubation success rates of emergency medicine residents: a prospective descriptive study. BMC emergency medicine. 2011;11(1):1-6. 
7. Hagberg C, Gabel JC, Connis R. Difficult Airway Society 2015 guidelines for the management of unanticipated difficult intubation in adults: not just another algorithm. In: Oxford University Press; 2015.

8. Nielsen JR, Lim K-S. Increasing the Scope on Difficult Airways: What About Mask Ventilation? Anesthesia $\&$ Analgesia.2019;129(3):e109.

9. Sreekantha D, Saldanha RS, Krishnappa JG, Mehandale SG, Glen RRC, Prajna M. Predicting difficulties in Mask Ventilation using Machine Learning techniques. Paper presented at: 2019 IEEE International Conference on Distributed Computing, VLSI, Electrical Circuits and Robotics (DISCOVER)2019.

10. Botes L, Jacobs J, Rademeyer R, Van der Merwe S, Van Heerden L, Diedericks B. The effect of different anaesthetic mask shapes on the anatomical dead space using infant, child and adult part-task trainers.Southern African Journal of Anaesthesia and Analgesia.2018;24(5):145-147.

11. Gerstein NS, Carey MC, Braude DA, et al. Efficacy of facemask ventilation techniques in novice providers. Journal of clinical anesthesia. 2013;25(3):193-197.

12. Riggle JD, McCrory B, Wadman M, et al. Comparison of muscle exertion and fatigue between standard bag valve mask and NuMask. Paper presented at: Proceedings of the Human Factors and Ergonomics Society Annual Meeting2012.

13. McCrory B, Lowndes BR, Thompson DL, et al. Workload comparison of intraoral mask to standard mask ventilation using a cadaver model. Paper presented at: Proceedings of the Human Factors and Ergonomics Society Annual Meeting2012.

14. Nimmagadda U, Salem M, Hsu E, Knezevic NN. The New Mask Is as Effective as the Classic Face Mask in Achieving Maximal Preoxygenation.

15. Amack AJ, Barber GA, Ng PC, Smith TB, April MD. Comparison of ventilation with one-handed mask seal with an intraoral mask versus conventional cuffed face mask in a cadaver model: a randomized crossover trial. Annals of emergency medicine. 2017;69(1):12-17.

16. Bach JR, Saporito LR. Cardiopulmonary Resuscitation Interface Adapted for Postextubation Continuous Noninvasive Ventilatory Support.American journal of physical medicine 63 rehabilitation.2015;94(9):e80-e83.

17. McCrory B, Lowndes BR, Thompson DL, et al. Crossover assessment of intraoral and cuffed ventilation by emergency responders. Military medicine. 2019;184(Supplement_1):310-317.

18. Blake DF, Crowe M, Lindsay D, Brouff A, Mitchell SJ, Pollock NW. Comparison of tissue oxygenation achieved breathing oxygen from a demand valve with four different mask configurations. Diving and hyperbaric medicine. 2018;48(4):209.

19. Nagappa M, Wong J, Singh M, Wong DT, Chung F. An update on the various practical applications of the STOP-Bang questionnaire in anesthesia, surgery, and perioperative medicine. Current opinion in anaesthesiology. 2017;30(1):118.

20. Han R, Tremper KK, Kheterpal S, O'Reilly M. Grading scale for mask ventilation. The Journal of the American Society of Anesthesiologists. 2004;101(1):267-267.

21. Hart SG, Staveland LE. Development of NASA-TLX (Task Load Index): Results of empirical and theoretical research. In: Advances in psychology. Vol 52. Elsevier; 1988:139-183.

22. Coule P, Mazzoli A, Todaro J. 465: Comparison of a Novel Intra-Oral Mask (NuMask(r)) to Standard Mask Ventilation Using a Cadaver Model.Annals of Emergency Medicine. 2010;3(56):S150-S151.

23. El-Orbany M, Woehlck HJ. Difficult mask ventilation.Anesthesia \& analgesia. 2009;109(6):1870-1880.

Table 1: Demographic and anthropometric characteristics of the patients 


\begin{tabular}{|c|c|c|c|c|}
\hline Parameter & Mean $\pm \mathrm{SD}$ & Med(Min-Max) & Parameter & $\mathrm{n}(\%)$ \\
\hline $\operatorname{Age}(y)$ & $42.94 \pm 13.24$ & $43(18-78)$ & $\operatorname{Gender}(\mathbf{F} / \mathbf{M})$ & $71 / 73(49.3 / 50.7)$ \\
\hline Weight $(\mathrm{kg})$ & $77.93 \pm 12.73$ & $77(50-123)$ & ASA I/II/III & $22 / 121 / 1(15.3 / 84 / 0.7)$ \\
\hline Height $(\mathrm{cm})$ & $169.51 \pm 7.70$ & $170(150-187)$ & $\begin{array}{l}\text { Mallampati } \\
\text { I/II/III }\end{array}$ & $49 / 74 / 21(34 / 51.4 / 14$. \\
\hline $\operatorname{BMI}\left(\mathrm{kg} \cdot \mathrm{cm}^{-2}\right)$ & $26.73 \pm 4.41$ & $26(18-41)$ & $\begin{array}{l}\text { Low OSAS risk } \\
\text { (STOP- } \\
\text { BANG }<3 \text { ) }\end{array}$ & $107(74.3)$ \\
\hline $\mathrm{NC}(\mathrm{cm})$ & $37.62 \pm 3.50$ & $37.50(28-48)$ & $\begin{array}{l}\text { High OSAS risk } \\
\text { (STOP- } \\
\text { BANG }>3 \text { ) }\end{array}$ & $37(25.7)$ \\
\hline $\operatorname{TMD}(\mathrm{cm})$ & $7.66 \pm 1.24$ & $8(4-12)$ & & \\
\hline $\operatorname{SMD}(\mathrm{cm})$ & $15.40 \pm 1.67$ & $15.5(12-19)$ & & \\
\hline $\mathrm{HMD}(\mathrm{cm})$ & $5.49 \pm 1.03$ & $5.50(2-9)$ & & \\
\hline IID $(\mathrm{cm})$ & $4.67 \pm 0.71$ & $5(3-7)$ & & \\
\hline
\end{tabular}

Data are expressed as mean \pm standard deviation or number (percentage). BMI, Body mass index ; NC, neck circumference; TMD, thyromental distance; SMD, sternomental distance; HMD, hyo-mental distance; IID, interincisor distance

Table 2: Comparison of the effectiveness of the ventilation between CFM and IOM in terms of SpO2\%, EtCO2, TV and LV.

\begin{tabular}{llllll}
\hline & Classic Face Mask & Classic Face Mask & Intraoral Mask & Intraoral Mask & \\
\hline & Mean \pm SD & Med(Min-Max) & Mean \pm SD & Med (Min-Max) & $\mathbf{p}^{+}$ \\
$\mathrm{SpO}_{2}$ & $99.46 \pm 0.88$ & $100(96-100)$ & $99.44 \pm 0.93$ & $100(96-100)$ & 0.572 \\
$\mathrm{EtCO}_{2}$ & $33.81 \pm 4.32$ & $34(6-44)$ & $33.59 \pm 4.35$ & $33(3-45)$ & 0.175 \\
$\mathrm{TV}$ & $430.85 \pm 154.87$ & $430(100-850)$ & $481.92 \pm 173.99$ & $500(50-910)$ & $\mathbf{0 . 0 0 0}$ \\
$\mathrm{LV}$ & $159.38 \pm 146.31$ & $110(0-720)$ & $71.50 \pm 91.17$ & $40(0-470)$ & $\mathbf{0 . 0 0 0}$ \\
\hline
\end{tabular}

${ }^{+}$Wilcoxon test/ Paired Samples T test; ${ }^{*}<0.05$ (SD, Standard deviation, Min; Minimum, Max; Maximum, $\mathrm{SpO}_{2}$ peripheral oxygen saturation, ETCO2 End tidal carbondioxyde, TV; Expiratory tidal volume, LV Leak volume)

Table 3: Comparison of the Classic face mask and Intraoral mask in terms of the ventilation success using the Percentage of the Patients with Han Scale=I

\begin{tabular}{llll}
\hline & Successful ventilation for Classic face mask & Successful ventilation for Intraoral mask & \\
\hline Han Scale $=\mathrm{I}$ & $84(58.3)$ & $123(85.4)$ & $\mathbf{0 . 0 0 0}^{*}$ \\
\hline
\end{tabular}

Data are expressed as number (percentage) ${ }^{*}$ McNemar Test $\mathrm{p}<0.005$

Table 4: Comparison of patient characteristics between successful (Han Scale=1) and unsuccessful mask ventilation (Han Scale $>1$ ) in classic face mask ventilation

\begin{tabular}{lll}
\hline & Successful Classic Face Mask Ventilation (Han Scale=1) $\mathrm{n}=84(58.3 \%)$ & Successful Classic Face Mask Ven \\
\hline Parameter & Mean \pm SD & Med(Min-Max $)$ \\
Age(y) & $41.19 \pm 12.37$ & $40(18-70)$
\end{tabular}




\begin{tabular}{lll}
\hline & Successful Classic Face Mask Ventilation (Han Scale=1) $\mathrm{n}=84(58.3 \%)$ & Successful Classic Face Mask Ven \\
\hline Weight $(\mathrm{kg})$ & $75.67 \pm 12.30$ & $75(50-123)$ \\
Height $(\mathrm{cm})$ & $168.73 \pm 7.49$ & $168(150-187)$ \\
BMI $\left(\mathrm{kg} . \mathrm{cm}^{-2}\right)$ & $26.18 \pm 4.13$ & $26(19-37)$ \\
NC $(\mathrm{cm})$ & $36.83 \pm 3.17$ & $36.5(28-45)$ \\
TMD $(\mathrm{cm})$ & $7.63 \pm 1.25$ & $8(4-10)$ \\
SMD $(\mathrm{cm})$ & $15.32 \pm 1.65$ & $15.5(12-19)$ \\
HMD $(\mathrm{cm})$ & $5.43 \pm 1.02$ & $6(2-7)$ \\
$\mathrm{IID}(\mathrm{cm})$ & $4.68 \pm 0.76$ & $5(3-7)$ \\
\hline
\end{tabular}

$+\mathrm{T}$ Test/ *Mann-Whitney U Test for $\mathrm{p}<0.005$ (SD, Standard deviation, Min; Minimum, Max; Maximum; BMI, Body mass index ;NC, neck circumference; TMD, thyromental distance; SMD, sternomental distance; HMD, hyo-mental distance; IID, interincisor distance)

Table 5: Comparison of patient characteristics between successful (Han Scale=1) and unsuccessful mask ventilation (Han Scale $>1$ ) in classic face mask ventilation

\begin{tabular}{|c|c|c|c|c|c|}
\hline & $\begin{array}{l}\text { Successful } \\
\text { Classic Face } \\
\text { Mask } \\
\text { Ventilation } \\
(\text { Han Scale=1) } \\
\mathrm{n}=84(58.3 \%)\end{array}$ & $\begin{array}{l}\text { Unsuccessful } \\
\text { Classic Face } \\
\text { Mask } \\
\text { Ventilation } \\
(\text { Han Scale }>1) \\
\mathrm{n}=60(41.7 \%)\end{array}$ & $\mathrm{P}+$ & $\mathrm{P}+$ & $\mathrm{P}+$ \\
\hline Gender(F/M) & $43 / 41(51,2 / 48.8)$ & $28 / 32(46.7 / 53.3)$ & 0.592 & 0.592 & 0.592 \\
\hline ASA I/II/III & $17 / 66 / 1(20.2 / 78.6 /$ & $15255 / 0(8.3 / 91.7 / 0)$ & 0.076 & 0.076 & 0.076 \\
\hline $\begin{array}{l}\text { Mallampati } \\
\text { I/II/III }\end{array}$ & $36 / 38 / 10(42.9 / 45.2$ & $/ 1131 / .9 \varnothing / 11(21.7 / 60 / 1$ & $(8.30) 29 *$ & $0.029^{*}$ & $0.029 *$ \\
\hline $\begin{array}{l}\text { Low OSAS risk } \\
(\text { STOP- } \\
\text { BANG }<3) \text { High } \\
\text { OSAS risk } \\
(\text { STOP- } \\
\text { BANG }>3)\end{array}$ & $71(84.5) 13(15.5)$ & $36(60) 24(40)$ & $0.001^{*}$ & $0.001 *$ & $0.001 *$ \\
\hline Beardless Only & $73(86.9) 8(9.5)$ & $45(75) 11(18.3)$ & 0.163 & & \\
\hline Mustache Beard & $3(3.6)$ & $4(6.7)$ & & & \\
\hline
\end{tabular}

Data are expressed as number (percentage) F, Female; M, Male; OSAS, Obstructive Sleep Apnea Syndrome + Ki Kare Test/ Fisher's Exact Test $* \mathrm{p}<0.05$

Table 6: Comparison of patient characteristics between successful (Han Scale=1) and unsuccessful mask ventilation (Han Scale $>1$ ) in intraoral mask ventilation

\begin{tabular}{lll}
\hline & Successful Intraoral Mask Ventilation (Han Scale=1) $\mathrm{n}=123(58.3 \%)$ & Successful Intraoral Mask Ventilatio \\
\hline Parameter & Mean \pm SD & Med(Min-Max) \\
Age $(\mathrm{y})$ & $42.18 \pm 13.34$ & $43(18-78)$ \\
Weight $(\mathrm{kg})$ & $77.15 \pm 12.19$ & $77(50-123)$ \\
Height $(\mathrm{cm})$ & $170.02 \pm 7.68$ & $170(150-187)$ \\
BMI $\left(\mathrm{kg} . \mathrm{cm}^{-2}\right)$ & $26.29 \pm 4.23$ & $26(18-37)$ \\
NC $(\mathrm{cm})$ & $37.60 \pm 3.43$ & $38(28-48)$
\end{tabular}




\begin{tabular}{lll}
\hline & Successful Intraoral Mask Ventilation (Han Scale=1) $\mathrm{n}=123(58.3 \%)$ & Successful Intraoral Mask Ventilatio \\
\hline TMD $(\mathrm{cm})$ & $7.60 \pm 1.21$ & $8(4-12)$ \\
SMD $(\mathrm{cm})$ & $15.47 \pm 1.71$ & $16(12-19)$ \\
$\mathrm{HMD}(\mathrm{cm})$ & $5.43 \pm 1.02$ & $5(2-7)$ \\
$\mathrm{IID}(\mathrm{cm})$ & $4.67 \pm 0.72$ & $5(3-7)$ \\
\hline
\end{tabular}

${ }^{+} \mathrm{T}$ Test $\mathrm{p}<0.005$; (SD; Standard deviation, Med; Median, Min; Minimum, Max; Maximum, BMI; Body mass index, NC; neck circumference, TMD; thyromental distance; SMD, sternomental distance; HMD, hyo-mental distance; IID, interincisor distance)

Table 7: Comparison of patient characteristics between successful (Han Scale=1) and unsuccessful mask ventilation (Han Scale >1) in intraoral mask ventilation

\begin{tabular}{|c|c|c|c|c|c|}
\hline & $\begin{array}{l}\text { Successful } \\
\text { Intraoral Mask } \\
\text { Ventilation(Han } \\
\text { Scale=1) n= } 123 \\
(85.4 \%)\end{array}$ & $\begin{array}{l}\text { Unsuccessful } \\
\text { Intraoral Mask } \\
\text { Ventilation(Han } \\
\text { Scale }>1) \mathrm{n}=21 \\
(14.6 \%)\end{array}$ & $\mathrm{P}+$ & $\mathrm{P}+$ & $\mathrm{P}+$ \\
\hline Gender(F/M) & $57 / 66(46.3 / 53.7)$ & $14 / 7(66.7 / 33.3)$ & 0.085 & 0.085 & 0.085 \\
\hline ASA I/II & $21 / 102 / 0(17.1 / 82.9$ & $/ 10) 19 / 1(4.8 / 90.5 / 4$ & 80.064 & 0.064 & 0.064 \\
\hline $\begin{array}{l}\text { Mallampati } \\
\text { I/II/III }\end{array}$ & $46 / 62 / 15(37.4 / 50.4$ & $31 / 212) 6(14.3 / 57.1 /$ & $2806043^{*}$ & $0.043^{*}$ & $0.043^{*}$ \\
\hline $\begin{array}{l}\text { Low OSAS risk } \\
(\text { STOP- } \\
\text { BANG }<3) \text { High } \\
\text { OSAS risk } \\
(\text { STOP- } \\
\text { BANG }>3)\end{array}$ & $93(75.6) 30(24.4)$ & $14(66.7) 7(33.3)$ & 0.386 & 0.386 & 0.386 \\
\hline Beardless Only & $100(81.3)$ & $18(85.7) 2(9.5)$ & 0.894 & & \\
\hline Mustache Beard & $17(13.8) 6(4.9)$ & $1(4.8)$ & & & \\
\hline
\end{tabular}

Data are expressed as number (percentage) F, Female; M, Male; OSAS, Obstructive Sleep Apnea Syndrome + Ki Kare Test/ Fisher's Exact Test ${ }^{*} \mathrm{p}<0.05$

Table 8: Comparison of the anxiety and workload assessment of the practitioners with STAI and NASATLX for Classical face mask and Intraoral mask

\begin{tabular}{llllll}
\hline & Classic Face Mask & Classic Face Mask & IntraOral Mask & IntraOral Mask & IntraOral Mas \\
\hline & Mean \pm SD & Med(Min-Max) & Med(Min-Max) & Mean \pm SD & Mean \pm SD \\
STAI-TX1 & $29.56 \pm 6.59$ & $27.5(20-44)$ & $31.67 \pm 8.13$ & $31.67 \pm 8.13$ & $30.5(20-50)$ \\
Nasa-TLX Total & $28.11 \pm 5.59$ & $27(14-42)$ & $31.17 \pm 8.69$ & $31.17 \pm 8.69$ & $29(16-52)$ \\
NASA-Mental Demand & $3.53 \pm 1.71$ & $3(1-8)$ & $4.19 \pm 2.34$ & $4.19 \pm 2.34$ & $4(1-10)$ \\
NASA-Physical Demand & $5.06 \pm 2.14$ & $5(1-10)$ & $5.39 \pm 2.37$ & $5.39 \pm 2.37$ & $5(1-10)$ \\
NASA-Temporal Demand & $4.03 \pm 2.14$ & $3(1-10)$ & $4.36 \pm 2.38$ & $4.36 \pm 2.38$ & $4(1-10)$ \\
NASA-Effort & $4.25 \pm 1.71$ & $4.5(1-8)$ & $5.08 \pm 2.38$ & $5.08 \pm 2.38$ & $5(1-10)$ \\
NASA-Performance & $8.39 \pm 1.64$ & $9(2-10)$ & $8.75 \pm 1.18$ & $8.75 \pm 1.18$ & $9(6-10)$ \\
NASA-Frustration & $2.94 \pm 1.41$ & $3(1-8)$ & $3.50 \pm 2.08$ & $3.50 \pm 2.08$ & $3(0-9)$ \\
\hline
\end{tabular}


NASA-TLX; The National Aeronautics and Space Administration-Task Load Index, STAI-TX1; State Trait Anxiety Inventory, SD; Standard Deviation, Min; Minimum, Max; Maximum ( ${ }^{+}$Wilcoxon test; ${ }^{*} \mathrm{p}<0.05$ )

Figure 1 : Classical Face Mask Ventilation

Figure 2: Intraoral Mask Ventilation

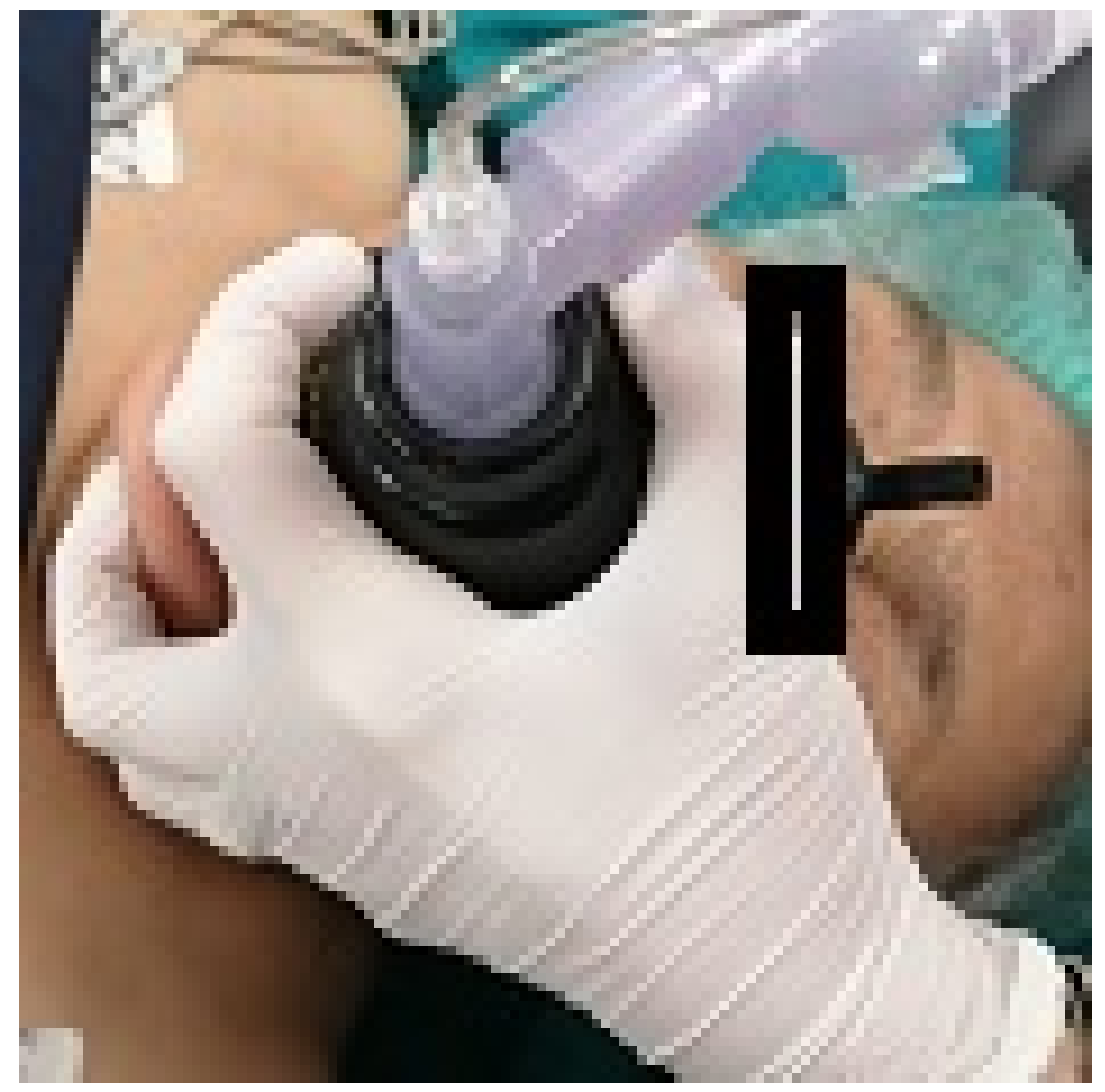




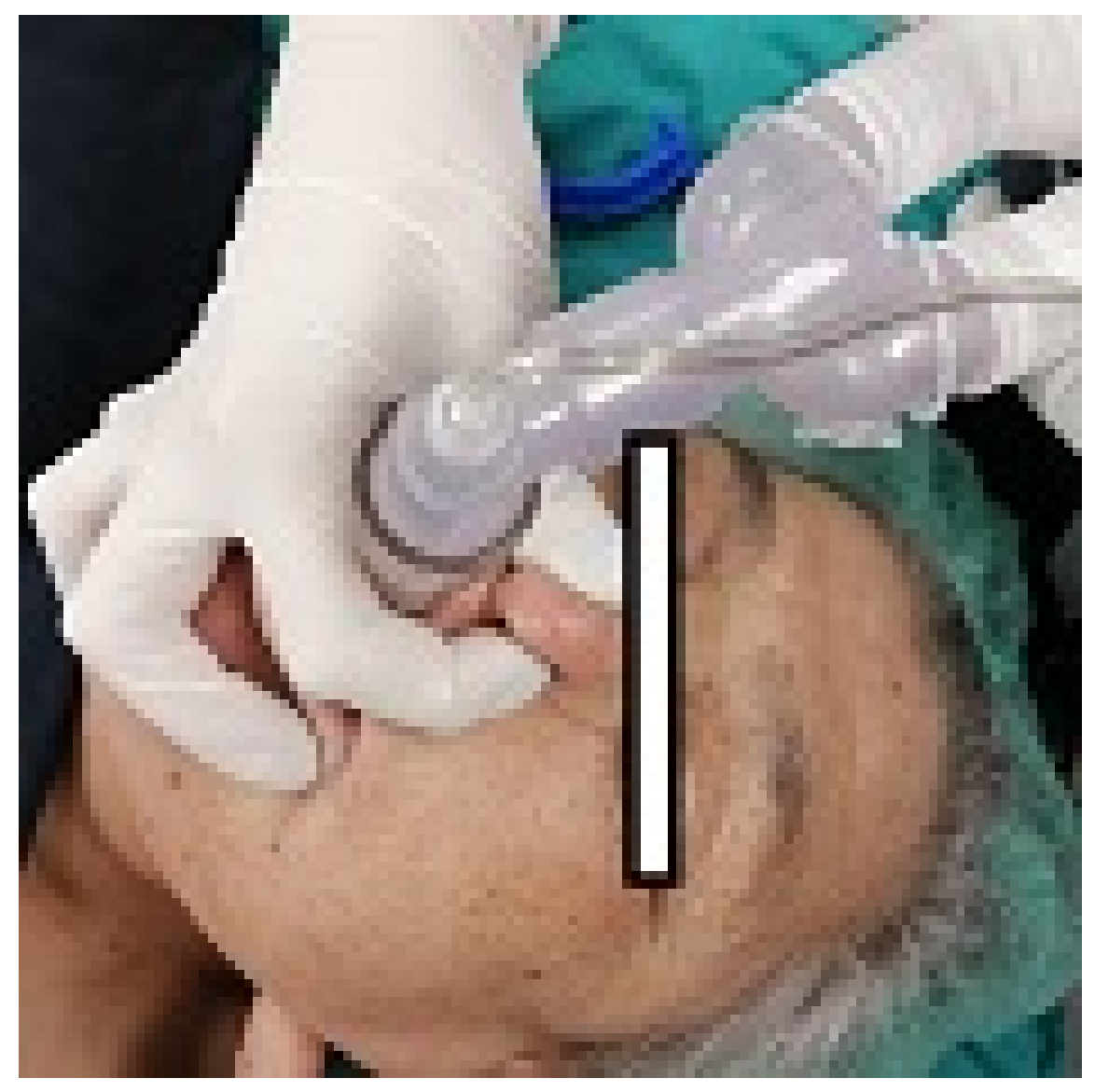

